\title{
Polycentrisme in lokale besluitvorming over duurzame energie: de casus slimme netten
}

I. (Imke) Lammers en M.J. (Maarten) Arentsen

\section{Samenvatting}

De energieplanning en de realisatie van nieuwe energetische infrastructuur is een zaak geworden van vele actoren. De lokale setting is polycentrisch geworden. Tegen deze achtergrond hebben we een antwoord gezocht op de vraag naar de mogelijke gevolgen van een polycentrische lokale besluitvormingsarena op het realiseren van een duurzame energietransitie, in het bijzonder de implementatie van slimme netten. Polycentrisme wordt gekenmerkt door configuraties met eenheden die multi-level, multi-purpose, multi-sectoral en multi-functional zijn. De werking van deze configuraties kan worden beoordeeld met behulp van vier criteria: controle, efficiëntie, politieke vertegenwoordiging en lokale zelfbeschikking. Met behulp van deze criteria hebben we twee cases geanalyseerd. Beide cases hebben laten zien dat de gevolgen van polycentrisme wisselend zijn en dat ook de score op de vier criteria verschilt. Onze analyse laat zien dat de polycentrische configuratie spanningen kent tussen enerzijds controle en efficiëntie en anderzijds zelfbeschikking en politieke vertegenwoordiging. Dit was voor ons reden om een beter institutioneel ontwerp voor de lokale polycentrische arena te bepleiten met behulp van de zeven rules-in-use van Elinor Ostrom. Haar ontwerp is universeel maar vraagt specifieke lokale toepassing. Op deze manier kan meer recht gedaan worden aan de lokale omstandigheden met vooruitzicht op effectieve resultaten.

\section{Inleiding}

Nieuwbouw en renovatie en de daarbij behorende energieplanning is zaak geworden van vele actoren. De opkomst van deze polycentrische arena's is een gevolg van vier recente ontwikkelingen in de energievoorziening, in het bijzonder in de elektriciteitsvoorziening: liberalisering, duurzame energiebronnen, lokale energiegemeenschappen, en slimme netten (smart grids). Liberalisering is het proces van stapsgewijs omzetting van monopolie naar markt organisatie in de elektriciteitsvoorziening (Arentsen \& Künneke, 2001). Naast de liberalisering heeft de duurzame energie-ambitie bijgedragen aan een toename van het aantal duurzame energiebronnen en aanbieders van elektriciteit op de Nederlandse elektriciteitsmarkt. Verder zijn lokaal energiegemeenschappen ontstaan die regie willen voeren over hun eigen lokale (duurzame) energievoorziening. Een vierde te noemen ontwikkeling is de opkomst van smart grid technologie in met name elektriciteitsvoorziening. Daarbij gaat het om intelligent management van vraag en aanbod van elektriciteit door middel van communicatietechnologie. 
Door de vier bovengenoemde ontwikkelingen wordt het steeds drukker in de lokale arena waarin wordt besloten over energetische infrastructuren. Sommige actoren moeten meepraten en meebeslissen op grond van hun wettelijke verantwoordelijkheden, anderen kunnen meepraten op grond van bijvoorbeeld kennis en vaardigheden en weer anderen willen meepraten omdat hun belangen in het geding zijn. De lokale arena heeft dus niet alleen meer actoren gekregen, maar ook meer belangen, wensen, verlangens en ambities. Kortom de arena is polycentrisch geworden.

In dit artikel verkennen we een polycentrische lokale beleidsarena en mogelijke implicaties voor de invoering van smart grid technologie. We beschouwen de invoering van smart grid technologie als onderdeel van de lokale energietransitie: de lokale besluitvorming over nieuwe energie-infrastructuur gaat eigenlijk steeds meer over de vraag hoe een duurzame energievoorziening lokaal kan worden gerealiseerd met smart grid technologie als middel voor effectief en efficiënt energy management.

In deze bijdrage beantwoorden we daarom de vraag welke mogelijke gevolgen een polycentrische lokale besluitvormingsarena kan hebben voor het realiseren van een duurzame energietransitie, in het bijzonder de implementatie van slimme netten. Wij zijn hierbij vooral geïnteresseerd in de gevolgen van de uitbreiding van het aantal actoren voor de aard en kwaliteit van lokale energieplanning. We beantwoorden de vraag zowel theoretisch als empirisch met behulp van twee case studies waarin componenten van smart grid technologie centraal staan. In de ene case gaat het om het testen en in de andere case om de implementatie van technische smart grid componenten. In de volgende paragraaf introduceren we kort het kernidee van polycentrisme zoals destijds geïntroduceerd door Vincent en Elinor Ostrom. Vervolgens analyseren en vergelijken we beide case studies en formuleren suggesties om de lokale polycentrische beleidsarena van energietransitie te verbeteren. We sluiten af met een aantal conclusies.

\section{Polycentrisme}

Het begrip polycentrisme is nauw verbonden met het werk van Vincent en Elinor Ostrom. Beide hebben hun leven lang onderzoek gedaan naar zogenoemde polycentrische configuraties die zich kenmerken door een verscheidenheid aan actoren die in een bepaalde relatie tot elkaar staan die niet kan worden gekwalificeerd als hiërarchie of als markt (Toonen, 2010). In de eigen woorden van Vincent Ostrom: "many centers of decision-making which are formally independent of each other" (V. Ostrom, Tiebout, \& Warren, 1961, p. 831). Daarmee plaatste Vincent Ostrom polycentrisme tegenover monocentrisme dat kenmerkend is voor een hiërarchische ordening. De Ostrom's hebben in hun 
vroege werk laten zien dat het idee van monocentrisme als één bestuurscentrum bijvoorbeeld de besluitvorming over de stedelijke ontwikkeling in de VS niet afdoende kon verklaren. ${ }^{1}$ Met hun levenslange onderzoek hebben ze een school gesticht, de Bloomington School, die tot op de dag van vandaag bestaat. Naast Vincent en later Elinor Ostrom, hebben anderen bijgedragen aan de conceptuele ontwikkeling en de empirische onderbouwing van polycentrisme (Aligica \& Tarko, 2012; McGinnis, 2011b; McGinnis \& Ostrom, 2012; E. Ostrom, 2010a, 2010b; Toonen, 1988). Polycentrisme van de Ostroms is op een aantal aspecten bekritiseerd. Volgens McGinnis (2009/2011) die de kritiek heeft samengevat, onderbelicht polycentrisme macht en machtsverdeling en vraagt zich onvoldoende af of regels democratisch tot stand zijn gekomen. Wij willen daarom betonen dat zelfbeschikking niet altijd tot rechtvaardige uitkomsten leidt en polycentrisme geen panacee is en een tijdsinvestering (kosten) vraagt (McGinnis, 2009/2011; E. Ostrom, 2010b).

McGinnis (2011a) geeft een goed overzicht van de kenmerken van de eenheden in een polycentrische configuratie: de eenheden zijn multi-level, multi-purpose, multi-sectoral ${ }^{2}$ en multi-functional. Multifunctioneel ${ }^{3}$ houdt in dat productie en aanbod van (publieke) goederen en diensten gescheiden zijn. Daarnaast kunnen er speciale eenheden voor financiering, coördinatie, toezicht, sancties en geschillenbeslechting bestaan. Bij de productie en het verschaffen van (publieke) goederen moet volgens V. Ostrom et al. (1961) met vier criteria rekening gehouden worden: 1.) controle; 2.) efficiëntie; 3.) politieke vertegenwoordiging; en 4.) lokale zelfbeschikking. Controle houdt in dat actoren zeggenschap en jurisdictie hebben over het geografische gebied waar de samenwerking/het project plaatsvindt. Efficiëntie heeft betrekking op schaalvoordelen van de samenwerking en op de effectiviteit van het toezicht (bijvoorbeeld gezamenlijk management). Politieke vertegenwoordiging wordt gegarandeerd door "the inclusion of the appropriate political interests within the decisionmaking arrangements" (V. Ostrom et al., 1961, p. 836). Lokale zelfbeschikking verwijst naar de betrokkenheid en autonomie (beschikkingsrecht) van lokale gemeenschappen (self-governance).

Deze vier criteria benadrukken het onderliggende idee van polycentrisme: actoren die de ambitie hebben een collectief probleem op te lossen of een collectief doel te bereiken, moeten de mogelijkheid hebben om zelf te beslissen wie voor het waarmaken van de ambities nodig zijn (McGinnis, 2009/2011). Het optimale niveau van taakverdeling - vooral voor de productie en

\footnotetext{
${ }^{1}$ Hoewel Michael Polyani in 1951 in zijn boek The Logic of Liberty het concept polycentrisme bespreekt, waren het V. Ostrom et al. (1961) die het concept op de bestuurs- en beleidswetenschappelijke agenda hebben gezet. 2 'Multi-sectoraal' wordt m.b.t. polycentrisme als vorm van coördinatie gedefinieerd: publiek, privé, vrijwillig, of gemeenschappelijk (McGinnis, 2011a).

${ }^{3}$ Dit aspect is ook één van E. Ostrom (1993) haar acht 'design principles' voor duurzaam beheer van collectieve goederen, door haar 'nested enterprises' genoemd.
} 
verschaffing van goederen en diensten - varieert hierbij van taak tot taak (Toonen, 1988). Dit kan ertoe leiden dat uiteindelijk een diversiteit aan formele en informele organisaties ontstaat, bijvoorbeeld een configuratie van bestaande publieke autoriteiten, nieuwe instituties, en informele (lokale) samenwerkingsverbanden.

Zulke configuraties zijn doorgaans de uitkomst van (competitieve) onderhandelingen en overeenkomsten tussen de betrokken actoren. Door interacties bepalen de betrokken individuen zelf de 'rules of the game' en de manier waarop overeenkomsten en institutionele mechanismen gecreëerd, gehandhaafd en veranderd worden. Voor het succes van een polycentrische configuratie is het belangrijk dat actoren mogelijkheden hebben om regels die hun situatie beïnvloeden, te kunnen bepalen, in plaats van dat deze door buitenstaanders worden opgelegd. Voor de afbakening van de polycentrische setting is het vervolgens belangrijk dat alle betrokkenen eenzelfde stelsel van regels accepteren en zich daaraan ook onderwerpen (Aligica \& Tarko, 2012). Met behulp van Elinor Ostrom (2011) haar Institutional Analysis and Development (IAD) Framework kunnen deze regels (rules-inuse) ontwikkeld worden (zie verder paragraaf 5). Daarbij moet wel worden bedacht dat collectieve besluitvorming op basis van consensus "the dominance of the powerful and vested interests of the few over the many" [Fine, 2010 in (McGinnis, 2009/2011, p. 151)] kan bevorderen.

Polycentrisme heeft voordelen, waaronder samenwerking, 'self-governance', spreiding van macht, onderlinge controle ('checks and balances'), mogelijkheden tot innovatie en experimenteren en het ontwikkelen van lerend vermogen en onderling vertrouwen. Daardoor kan polycentrisme tot betere uitkomsten en prestaties leiden (E. Ostrom, 2010b). Nadeel is dat er veel van de partners wordt gevraagd in termen van overleg en onderhandeling. Ook is het zo dat de samenwerking vaak niet spontaan tot stand komt. De configuratie moet worden gecreëerd. Als dat eenmaal is gebeurd dan kunnen gezamenlijk innovatieve projecten worden gerealiseerd.

Dit zou betekenen dat een polycentrische configuratie voor energietransitie inspirerend kan werken en tot goede resultaten zou kunnen leiden. Polycentrisme impliceert immers dat gebruik wordt gemaakt van de diversiteit aan kennis, ervaring en vaardigheden aanwezig in de lokale setting. Mits productief aangewend, kunnen in zo'n diversiteit, innovatieve oplossingen ontstaan. Nederland kent inmiddels op het lokale niveau tal van voorbeelden waarbij samenwerkende partijen mooie duurzame oplossingen bedenken bij nieuwbouw en renovatie van woningen en wijken, maar ook om straat, buurt, wijk of dorp duurzamer te maken door middel van lokale elektriciteitsproductie met duurzame bronnen. In toenemende mate zijn het burgers die daartoe initiatieven nemen en daarbij zelf de regie 
in handen nemen en houden. Samenwerking met overheden en bedrijven is echter onontbeerlijk. Elektriciteit, gas en warmte zijn speciale producten die door hooggekwalificeerde bedrijven worden aangeboden. De technische coördinatie van vraag en aanbod van deze producten geschiedt door middel van gecompliceerde technische infrastructuren. Er zijn hoogwaardige technische kennis en vaardigheden nodig om op deze product "markten" te kunnen opereren. Die kennis en vaardigheden hebben lokale burgerinitiatieven doorgaans niet zelf in huis en zoeken om die reden samenwerking met netbedrijven, energiebedrijven en overheden. Op deze manier zijn in Nederland inmiddels lokaal vele polycentrische configuraties ontstaan, waarin het lokale burgerinitiatief samen met professionals werkt aan verduurzaming van de leefomgeving. Succesvolle voorbeelden zijn Lochem Energie en vele anderen (Arentsen \& Bellekom, 2014; Hoppe, Graf, Warbroek, Lammers, \& Lepping, 2015; Oteman, Wiering, \& Helderman, 2014). Anderzijds kunnen zulke lokale polycentrische configuraties ontstaan rondom nieuwbouw en renovatieprojecten of worden geïnitieerd door subsidieprogramma's.

\section{Twee case studies}

Vanuit energietransitie perspectief is de vraag relevant wat de gevolgen van een polycentrische lokale besluitvormingsarena zijn voor de implementatie van smart grid technologie in Nederland. Implementatie van smart grid technologie is belangrijk voor de energietransitie, omdat daarmee winst in de productie en consumptie van elektriciteit kan worden gerealiseerd. Tegelijkertijd moet worden geconstateerd dat de invoering van smart grid technologie in Nederland nog niet echt van de grond is gekomen. Wel wordt er in projecten met componenten van de technologie geëxperimenteerd. Voor onze analyse hebben wij twee cases gekozen waarin er naast de technische smart grid component, sprake was van een polycentrische configuratie.

\subsection{IPIN project JEM Zwolle}

De eerste case is 'Jouw Energie Moment: Smart Grid met de consument' (kort JEM) uit Zwolle. JEM Zwolle was onderdeel van het 'Innovatieprogramma Intelligente Netten' (IPIN), waarmee het ministerie van Economische Zaken tussen 2011 en 2015 twaalf proeftuinen met slimme netten financieel heeft ondersteund (project budget van $€ 16$ miljoen).

Het JEM slim net project vond tussen januari 2012 en januari 2015 in de nieuw gebouwde Muziekwijk in Zwolle plaats. Netbeheerder Enexis was initiatiefnemer van het project en heeft - op verzoek van de overheid - projectpartners gezocht die ook het (collectieve) doel hadden om een smart grid in de Muziekwijk te implementeren en bereid waren om in het project te investeren. Uiteindelijk werden in 226 huurwoningen van woningcorporatie SWZ in de Muziekwijk slimme meters, energiedisplays 
(voorzien van een home energy management system, $\mathrm{HEMS}^{4}$ via bedrijf Flexicontrol en $\mathrm{CGI}$ ), slimme wasmachines en zonnepanelen geplaatst (Kobus, Klaassen, Kohlmann, Knigge, \& Boots, 2013). De bewoners konden vervolgens op de energiedisplays kiezen of hun wasmachines automatisch op het goedkoopste tijdstip of op het tijdstip met duurzame energie startte ${ }^{5}$ (Klaassen, Frunt, \& Slootweg, 2014). De polycentrische configuratie werd geïnstitutionaliseerd door een consortium te vormen bestaande uit Enexis, Woningstichting SWZ, energieleverancier Eneco, Flexicontrol en CGI. De bewoners uit de Muziekwijk en de nationale overheid (die een paar miljoen in de nieuwbouwwijk heeft geïnvesteerd) waren geen onderdeel van het consortium.

\subsection{Green Deal project Bothoven-Noord}

De tweede case is 'Green Deal Smart Energy Cities: Bothoven-Noord' (kort Bothoven-Noord) in de gemeente Enschede. Deze Green Deal is onderdeel van de overeenkomst tussen centrale overheid en samenleving met het doel een slimmere en duurzamere lokale energievoorziening - middels innovatie en lokale opwek - in 100.000 gebouwen in Nederland te realiseren (in 2019) . ${ }^{6}$

In november 2013 heeft de gemeente Enschede de overeenkomst 'Green Deal Smart Energy Cities' ondertekend. Om de doelen van deze Green Deal te realiseren moest de gemeente projecten voordragen en projectpartners zoeken. Omdat er al een projectgroep 'duurzaamheid' voor de wijk Bothoven-Noord in Enschede bestond en de drie projectgroep leden (medewerkers van woningcorporatie DeWoonplaats, woningcorporatie Domijn en de gemeente Enschede) graag een slim net in de wijk wilden realiseren, was de keuze voor een voorbeeld project snel gemaakt. Naast deze drie actoren werden netbeheerder Cogas en Enexis en Stichting Pioneering lid van de projectgroep. Na de start van het project in augustus 2014, zijn tot begin 2016 alleen slimme meters in de wijk geplaatst. Andere componenten van een slim net zijn nog niet geïmplementeerd.

\subsection{Dataverzameling \& analyse}

Gegevens over JEM Zwolle werden in februari en maart 2015 door middel van interviews met drie experts van netbeheerder Enexis verzameld en werden project documenten bestudeerd. De gegevens over het Bothoven-Noord project werden in juni en juli 2015 eveneens door middel van interviews

\footnotetext{
${ }^{4}$ Ook 'Energy Management System' (EMS) genoemd.

${ }^{5}$ Dynamische energietarieven werden toegepast. Het dynamisch energietarief was opgebouwd uit een dynamisch elektriciteitstarief (van Eneco) en een dynamisch netwerktarief (van Enexis). De energiebelasting en de btw die onderdeel van het energietarief uitmaakten, waren niet dynamisch.

${ }^{6}$ De Green Deal Smart Energy Cities is, naast vijf gemeenten (Amsterdam, Arnhem, Deventer, Eindhoven en Enschede), getekend door Netbeheer Nederland, het Ministerie van Economische Zaken en vier TKIs (Stichting TKI Switch2SmartGrids, Stichting TKI EnerGo, Stichting TKI Solar Energy, Stichting TKI Power2Gas, Stichting TKI ClickNL).
} 
verzameld. Alle zes projectgroep leden zijn geïnterviewd. Daarnaast heeft één van de auteurs gedurende 2015 en 2016 aan elf van de maandelijkse project vergaderingen deelgenomen.

De analyse is gebaseerd op de vier door V. Ostrom et al. (1961) voorgestelde criteria van polycentrisme: Controle, efficiëntie, politieke vertegenwoordiging en lokale zelfbeschikking. Voor de implementatie van slimme netten zijn eigenlijk vooral twee van de vier criteria van belang: efficiëntie en lokale zelfbeschikking. Efficiëntie geeft een indruk hoe productief een lokale configuratie oplossingen weet te realiseren. Zelfbeschikking geeft een beeld van de lokale autonomie en regie in en over het realisatieproces. Lokale zelfbeschikking kan echter onder druk komen te staan door betrokkenheid van niet-lokale actoren of door bovenlokale subsidieprogramma's die door criteria en eisen de lokale zelfbeschikking kunnen beperken. Kortom beide criteria efficiëntie en zelfbeschikking zijn belangrijke indicatoren om aard en kwaliteit van lokale polycentrische configuraties in de energietransitie te analyseren.

\section{Resultaten van de analyse}

De onderzoeksvraag hebben we in twee stappen beantwoord. Eerst hebben we de polycentrische kenmerken van de twee cases geanalyseerd en vervolgens hebben we beide cases op de vier criteria van polycentrisme gepositioneerd.

\subsection{Polycentrische kenmerken van beide cases}

In beide projecten zijn actoren op verschillende niveaus (multiple levels) betrokken, van lokale woningcorporaties, regionale netbeheerders tot het internationale bedrijf CGI in het geval van JEM. Er zijn multi-purpose eenheden aanwezig, actoren met territoriale jurisdictie (Enexis/Cogas, woningcorporaties, bewoners, overheid/gemeente) en actoren zonder territoriale jurisdictie. De projecten zijn duidelijk multi-sectoral: semipublieke organisaties (Enexis/Cogas, woningcorporaties, Eneco), de overheid (rijksoverheid en gemeente), private bedrijven en bewoners zijn betrokken. De multifunctionele kenmerken zijn vooral in het JEM project zichtbaar: de productie wordt door Eneco en bewoners gedaan, Enexis levert, alle consortiumleden financieren het project en de rijksoverheid is verantwoordelijk voor toezicht en geschillenbeslechting. In beide cases is de lokale configuratie polycentrisch te noemen. In tabel 1 zijn per case de details weergegeven.

\begin{tabular}{|l|l|l|}
\hline \multicolumn{1}{|c|}{ JEM Zwolle } & \multicolumn{1}{|c|}{ Bothoven-Noord } \\
\hline Multiple & Lokaal: SWZ, bewoners & Lokaal: woningcorporaties, gemeente, \\
levels & Regionaal: Enexis & Regionaal: Enexis, Cogas, Pioneering \\
\hline
\end{tabular}




\begin{tabular}{|c|c|c|}
\hline & $\begin{array}{l}\text { Nationaal: Eneco, Flexicontrol, rijks- } \\
\text { overheid } \\
\text { Globaal: CGI }\end{array}$ & \\
\hline $\begin{array}{l}\text { Multi- } \\
\text { purpose }\end{array}$ & $\begin{array}{l}\text { Territoriale jurisdictie: Enexis, SWZ, } \\
\text { bewoners, rijksoverheid } \\
\text { Non-territoriale jurisdictie: Eneco, CGI, } \\
\text { Flexicontrol }\end{array}$ & $\begin{array}{l}\text { Territoriale jurisdictie: Enexis, Cogas, } \\
\text { woningcorporaties, gemeente } \\
\text { Non-territoriale jurisdictie: Pioneering }\end{array}$ \\
\hline $\begin{array}{l}\text { Multi- } \\
\text { sectoral }\end{array}$ & $\begin{array}{l}\text { Privaat: bewoners, bedrijven } \\
\text { Publiek: rijksoverheid } \\
\text { Semipubliek: Enexis, Eneco, SWZ }\end{array}$ & $\begin{array}{l}\text { Privaat: Pioneering } \\
\text { Publiek: gemeente } \\
\text { Semipubliek: Enexis, woningcorporaties, } \\
\text { Cogas }\end{array}$ \\
\hline $\begin{array}{l}\text { Multi- } \\
\text { functional }\end{array}$ & $\begin{array}{l}\text { Verschaffing: Enexis } \\
\text { Productie: Eneco, bewoners } \\
\text { Toezicht/sancties: rijksoverheid } \\
\text { Cofinanciering: consortium leden }\end{array}$ & $\begin{array}{l}\text { Verschaffing: Enexis } \\
\text { (verder onduidelijk) }\end{array}$ \\
\hline
\end{tabular}

Tabel 1: Polycentrische kenmerken van beide cases

4.2 De positionering van beide cases op de vier criteria van polycentrisme

In tabel 2 zijn beide cases gepositioneerd op de vier criteria van polycentrisme. Hoe meer er sprake is van controle, efficiëntie, politieke vertegenwoordiging en lokale zelfbeschikking, des te succesvoller het polycentrische arrangement aldus de theorie (V. Ostrom et al., 1961). We kijken vanuit dit perspectief naar beide cases.

\begin{tabular}{|l|l|l|}
\hline & \multicolumn{1}{|c|}{ JEM Zwolle } & \multicolumn{1}{|c|}{ Bothoven-Noord } \\
\hline Controle & Enexis en woningcorporatie & $\begin{array}{l}\text { Enexis, woningcorporaties direct, } \\
\text { gemeente indirect }\end{array}$ \\
\hline Efficiëntie & Gezamenlijke investeringen & $\begin{array}{l}\text { Stakeholders } \\
\text { onduidelijkheden }\end{array}$ \\
\hline $\begin{array}{l}\text { Politieke } \\
\text { vertegenwoordiging }\end{array}$ & $\begin{array}{l}\text { Geen verkozen eenheid direct } \\
\text { betrokken }\end{array}$ & $\begin{array}{l}\text { Gemeente betrokken } \\
\text { Lokale } \\
\text { zelfbeschikking }\end{array}$ \\
\hline $\begin{array}{l}\text { Bewoners indirect betrokken (niet in } \\
\text { besluitvorming) }\end{array}$ & Geen bewoners betrokken \\
\hline
\end{tabular}

Tabel 2: Toepassing van vier polycentrische criteria op de twee case studies 
Volgens Vincent Ostrom kunnen actoren die jurisdictie hebben over het geografische gebied waar het project plaatsvindt controle uitoefenen. In beide smart grid projecten hebben op basis van deze definitie alleen Enexis (beheerder van de elektriciteitsnetten in de wijk) en de woningcorporaties (eigenaar van de woningen) directe controle in de projecten. De controle van Enexis en de woningcorporaties is echter beperkt omdat zij semipublieke organisaties zijn en daarom met door de overheid gestelde voorwaarden en beperkingen te maken hebben. Vooral met betrekking tot smart grid projecten besteedt de Autoriteit Consument en Markt (ACM) in toenemende mate aandacht aan het feit dat semipublieke organisaties geen commerciële activiteiten mogen ondernemen (ACM, 2015). Dit beperkt hun speelruimte om lokaal initiatief te nemen, wat voor de hand ligt omdat netbedrijven de technische expertise hebben om lokaal duurzame opties af te wegen. In BothovenNoord is de gemeente betrokken maar heeft geen directe jurisdictie over (onderdelen van) het project.

Volgens de polycentrische literatuur is er sprake van efficiëntie als de samenwerking schaalvoordelen oplevert en daardoor sneller tot resultaten kan leiden. Het JEM project lijkt in deze betekenis efficiënt te zijn uitgevoerd vanwege de gezamenlijke investeringen en het gecoördineerde management. Het Bothoven-Noord project lijkt meer problemen te hebben om schaalvoordelen te realiseren en efficiënt resultaten te boeken. $\mathrm{Er}$ is vooral veel onduidelijkheid over taken, verantwoordelijkheden en de verdeling van de kosten en de baten met als gevolg dat tussen augustus 2014 en maart 2016 alleen slimme meters werden geïnstalleerd. Het JEM project verliep efficiënter: tussen januari 2012 en januari 2015 werden in 226 woningen naast slimme meters energiedisplays, slimme wasmachines en zonnepanelen geïnstalleerd en beproefd met als resultaat een meer duurzaam energiegedrag van de bewoners. Uit de interviews bleek dat het proeftuinkarakter van het project, de beschikbare subsidie en de armslag om als semi-publieke organisatie te investeren, de efficiëntie hebben verhoogd.

In beide cases is door de betrokkenheid van gemeenteraden sprake van politieke vertegenwoordiging, maar deze stond in beide cases op afstand en had weinig invloed. Daarnaast was de lokale zelfbeschikking in beide cases niet optimaal door de afwezigheid van bewoners in het samenwerkingsverband. Bewoners werden niet in de besluitvorming betrokken. De interviews boden geen afdoende verklaring voor de reden van de afwezigheid van bewoners terwijl die essentieel zijn voor het goed functioneren van de beproefde smart grid technologie.

Wij kunnen concluderen dat JEM en Bothoven-Noord polycentrische configuraties zijn met een aantal specifieke kenmerken die van belang kunnen zijn voor de implementatie van slimme netten. In beide 
projecten is er sprake van een stakeholder die de regie neemt (netbeheerder Enexis/ gemeente Enschede). Ook onderschreven de betrokken actoren het gemeenschappelijk doel om een smart grid te implementeren. Er was veel draagvlak in beide projecten. Verder is de samenwerking in beide projecten geïnstitutionaliseerd en hebben de betrokkenen bij het JEM project gezamenlijk in het project geïnvesteerd - in het Bothoven-Noord project was de financiering nog niet geagendeerd. Beide cases laten ook zien dat de lokale zelfbeschikking in de vorm van bewoners, in beide projecten nauwelijks werd gerespecteerd. Dat is opvallend omdat juist bewoners steeds meer eigen regie over de inrichting van hun leefomgeving claimen. Lokale zelfbeschikking kan onder druk raken, bijvoorbeeld omdat de centrale overheid op de een of andere wijze bepalend blijft voor de besluitvorming op lokaal niveau. In beide cases is inderdaad sprake van externe interventie door de centrale overheid. In de JEM case door middel van subsidievoorwaarden en in de Bothoven-Noord case door de voorwaarden van de Green Deal. Gesteld kan worden dat de Green Deal in de BothovenNoord case de betrokkenen heeft geïnspireerd om het thema smart grid gezamenlijk op te pakken. Vervolgens werd het realiseren een aangelegenheid van lokale betrokkenen, die het eens konden worden over de invoering van de slimme meter, maar nog wel moeten praten over de lokale verdeling van de kosten en baten.

Beide cases vertonen kenmerken van een polycentrische configuratie, met een mix aan diversiteit in organisaties en perspectieven, een zekere mate van efficiëntie en betrokkenheid van, maar geen dominantie door democratische organen. Op het aspect zelfbeschikking van bewoners scoren beide cases minder omdat de bewoners geen onderdeel waren van de configuratie die de besluiten nam en uitvoerde.

Wat kunnen we nu leren van beide cases over de invloed van polycentrische configuraties op de energietransitie in Nederland? Helpen zulke configuraties de energietransitie vooruit of werken ze juist tegen? Onze beperkte analyse laat geen verregaande conclusies toe, maar laat wel zien dat de polycentrische configuratie spanningen kent tussen enerzijds controle en efficiëntie en anderzijds zelfbeschikking en politieke vertegenwoordiging. Gecontroleerd en efficiënt werken kan tot snelle resultaten leiden en daardoor relatief snel bijdragen aan de energietransitie. Het zoeken van een balans met zelfbeschikking en politieke vertegenwoordiging kan het proces vertragen, hetgeen vanuit transitieperspectief niet wenselijk is, maar vanuit democratisch perspectief juist wel. Belangrijk is om een goede balans te vinden tussen efficiëntie en democratie: meters maken door middel van een open democratisch proces. Het vinden van die balans is uitdagend, maar de vele lokale energiegemeenschappen in binnen- en buitenland laten zien hoe de balans in de praktijk gerealiseerd 
kan worden. Het structureren van de lokale dynamiek in een productieve open polycentrische configuratie is een belangrijke eerste stap om lokaal duurzame oplossingen te realiseren. In de volgende paragraaf geven we enkele suggesties.

\section{Rules-in-use voor een effectieve lokale aanpak van energietransitie}

Beide voorbeelden hierboven hebben laten zien dat er eigenlijk geen vaste institutionele kaders meer bestaan voor het initiëren en realiseren van een duurzame lokale energievoorziening. Energietransitie wordt meer en meer onderdeel van een bredere focus op duurzaamheid (Green Deal) of wordt opgepakt in het kader van een specifieke regeling (IPIN). Ook zijn er veel burgerinitiatieven die vanuit het niets opkomen om de lokale duurzaamheidsagenda op te pakken. Lokale energiegemeenschappen richten zich op duurzame energie door lokaal nieuwe organisaties voor productie en consumptie van duurzame elektriciteit, warmte en vervoer op te zetten. Elinor Ostrom's Institutional Analysis and Development (IAD) Framework kan behulpzaam zijn om lokaal nieuwe institutionele kaders op te zetten (E. Ostrom, 2011). Ostrom geeft een institutionele metataal die gebruikt kan worden om lokaal, tailormade, specifieke duurzame oplossingen te realiseren. De kern van het IAD framework bestaat uit zeven regels die volgens Ostrom lokaal naar eigen inzicht en behoefte (zelfbeschikking) ingevuld en gespecificeerd kunnen worden om effectieve en efficiënte polycentrische configuraties te ontwikkelen. Efficiëntie is belangrijk omdat er in Nederland echt stappen gezet moeten worden in het verduurzamen van de energievoorziening. Eigenlijk is het ontwerpen van een polycentrische lokale duurzaamheidsconfiguratie met behulp van de zeven regels niets anders dan heel gestructureerd en expliciet met elkaar afspreken hoe men wil samenwerken, wat ieders aandeel zal zijn en welke resultaten worden nagestreefd. Het bespreken van de configuratie zelf zou vooraf moeten gaan aan de inhoud van de samenwerking (wat men wil realiseren). Onze suggestie komt er op neer dat eerst de procesarchitectuur (wie doen mee, wat zijn ieders do's and dont's, hoe worden besluiten genomen) moet worden afgesproken en als dat klaar is, pas de vraag aan de orde moet komen wat er zal worden gedaan, met welk resultaat. Zo'n aanpak doet recht aan zelfbeschikking en dat is belangrijk voor het lokale draagvlak, maar vooral om het engagement van de samenleving, zichtbaar in de vele lokale initiatieven, recht te doen. Bovendien is de participatie van bewoners essentieel voor de werking van bijvoorbeeld een slim elektriciteitsnet: door een verandering in hun gedrag en specifiek in hun energievraag kan een slim net efficiënt werken.

Samengevat, onze verwachting is dat door het bepalen van regels de lokale energietransitie in Nederland kan verbeteren doordat er sneller en efficiënter stappen gezet kunnen worden en doordat 
het engagement van de burgermaatschappij veel beter benut kan worden, waardoor het lokale draagvlak groter kan worden. Dit wordt inmiddels ook wel erkend door de overheid, getuige de recente algemene maatregel van bestuur (AMvB) 'Besluit experimenten decentrale duurzame elektriciteitsopwekking' ${ }^{7}$. Dit besluit staat experimenten toe waarin verenigingen (coöperaties en verenigingen van eigenaars) lokaal productie en levering van duurzame elektriciteit lokaal in eigen hand kunnen nemen.

\section{Conclusie}

In dit artikel hebben we een antwoord gezocht op de vraag naar de mogelijke gevolgen van een polycentrische lokale besluitvormingsarena op het realiseren van een duurzame energietransitie, in het bijzonder de implementatie van slimme netten. Met behulp van de vier criteria van polycentrisme (controle, efficiëntie, politieke vertegenwoordiging en lokale zelfbeschikking) hebben we daarom twee cases geanalyseerd. Beide cases hebben laten zien dat de score op de vier criteria wisselend is en dat ook de gevolgen wisselend zijn. Onze analyse laat ook zien dat de polycentrische configuratie spanningen kent tussen enerzijds controle en efficiëntie en anderzijds zelfbeschikking en politieke vertegenwoordiging. Dit was voor ons reden om Ostrom's institutionele metataal aan te bevelen om lokaal de polycentrische configuratie rondom energietransitie te verbeteren. Ostrom's algemene kader vraagt om specifieke lokale toepassing en dat betekent dat de diversiteit van institutionele arrangementen in de energietransitie zal toenemen. Wij vinden dit een positieve ontwikkeling omdat diversiteit een belangrijke conditie is voor innovatie. Institutionele arrangementen die dit waarborgen kunnen daaraan bijdragen.

\section{Referenties}

ACM. (2015). ACM wil rem op commerciële activiteiten van netwerkbedrijven op de energiemarkt. Verkregen op 29-02-2016 van https://www.acm.nl/nl/publicaties/publicatie/14063/ACM-wilrem-op-commerciele-activiteiten-van-netwerkbedrijven-op-de-energiemarkt/

Aligica, P. D., \& Tarko, V. (2012). Polycentricity: From Polanyi to Ostrom, and Beyond. Governance, 25(2), 237-262. doi:10.1111/j.1468-0491.2011.01550.x

Arentsen, M. J., \& Bellekom, A. A. (2014). Power to the people: local energy initiatives as seedbeds of innovation? Energy, Sustainability and Society, 4(2).

Arentsen, M. J., \& Künneke, R. W. (2001). Dutch Negotiated Regulation: Conceptualisation and Illustration. In A. Midttun \& E. Svindland (Eds.), Approaches and Dilemmas in Economic Regulation (pp. 27-55). New York, NY, USA: Palgrave.

Hoppe, T., Graf, A., Warbroek, B., Lammers, I., \& Lepping, I. (2015). Local Governments Supporting Local Energy Initiatives: Lessons from the Best Practices of Saerbeck (Germany) and Lochem (The Netherlands). Sustainability, 7(2), 1900-1931.

\footnotetext{
${ }^{7}$ Ook 'Besluit Experimenten DDE' of 'Experimenteer AMvB' genoemd.
} 
Klaassen, E. A. M., Frunt, J., \& Slootweg, J. G. (2014). Method for evaluating smart grid concepts and pilots. Paper presented at the IEEE Young Researchers Symposium (YRS 2014), Ghent, Belgium.

Kobus, C., Klaassen, E., Kohlmann, J., Knigge, J., \& Boots, S. (2013, 6-9 Oct. 2013). Sharing lessons learned on developing and operating Smart Grid pilots with households. Paper presented at the Innovative Smart Grid Technologies Europe (ISGT EUROPE), 2013 4th IEEE/PES.

McGinnis, M. D. (2009/2011). Elinor Ostrom: Politics as Problem-Solving in Polycentric Settings. In D. Campus, G. Pasquino, \& M. Bull (Eds.), Maestri of political science (pp. 137-155). Colchester: ECPR Press.

McGinnis, M. D. (2011a). An Introduction to IAD and the Language of the Ostrom Workshop: A Simple Guide to a Complex Framework. Policy Studies Journal, 39(1), 169-183. doi:10.1111/j.15410072.2010.00401.x

McGinnis, M. D. (2011b). Networks of Adjacent Action Situations in Polycentric Governance. Policy Studies Journal, 39(1), 51-78. doi:10.1111/j.1541-0072.2010.00396.x

McGinnis, M. D., \& Ostrom, E. (2012). Reflections on Vincent Ostrom, Public Administration, and Polycentricity. Public Administration Review, 72(1), 15-25. doi:10.1111/j.15406210.2011.02488.x

Ostrom, E. (1993). Design principles in long-enduring irrigation institutions. Water Resources Research, 29(7), 1907-1912. doi:10.1029/92WR02991

Ostrom, E. (2010a). Beyond Markets and States: Polycentric Governance of Complex Economic Systems. American Economic Review, 100(3), 641-672. doi:doi: 10.1257/aer.100.3.641

Ostrom, E. (2010b). Polycentric systems for coping with collective action and global environmental change. Global Environmental Change, 20(4), 550-557. doi:http://dx.doi.org/10.1016/j.gloenvcha.2010.07.004

Ostrom, E. (2011). Background on the Institutional Analysis and Development Framework. Policy Studies Journal, 39(1), 7-27. doi:10.1111/j.1541-0072.2010.00394.x

Ostrom, V., Tiebout, C. M., \& Warren, R. (1961). The Organization of Government in Metropolitan Areas: A Theoretical Inquiry. American Political Science Review, 55(4), 831-842.

Oteman, M., Wiering, M., \& Helderman, J.-K. (2014). The institutional space of community initiatives for renewable energy: a comparative case study of the Netherlands, Germany and Denmark. Energy, Sustainability and Society, 4(1), 11.

Toonen, T. A. J. (1988). Monocentrisme, polycentrisme en de economie van het openbaar bestuur. Het werk van Vincent Ostrom. In A. F. A. Korsten \& T. A. J. Toonen (Eds.), Bestuurskunde. Hoofdfiguren en kernthema's. Leiden: Stenfert Kroese.

Toonen, T. A. J. (2010). Resilience in Public Administration: The Work of Elinor and Vincent Ostrom from a Public Administration Perspective. Public Administration Review, 70(2), 193-202. doi:10.1111/j.1540-6210.2010.02147.x 